\title{
CASAMENTO, MORALIDADE E TRANSGRESSÃO NA CIDADE DA BAÍA DE TODOS OS SANTOS: O CASO DE MARIA BARBOSA (1600-1614) \\ Helena Ribeiro da Silva' ${ }^{1}$; Adriana Dantas Reis ${ }^{2}$
}

${ }^{1}$ Bolsista PIBIC/FAPESB, Graduanda em Licenciatura em História, Universidade Estadual de Feira de Santana, e-mail: ribeiro.hw@gmail.com

${ }^{2}$ Orientadora, Departamento de Ciências Humanas e Filosofia, Universidade Estadual de Feira de Santana, email: adrihis@hotmail.com

PALAVRAS-CHAVE: Inquisição, casamento, transgressão.

\section{INTRODUÇÃO}

O presente trabalho está inserido na área de História, no campo da História Cultural, ou Sócio-cultural, bem como dos estudos de gênero, e tem como principal objeto de pesquisa o processo inquisitorial da ré Maria Barbosa, mulher parda, natural de Évora, casada com o ourives João da Cruz, filha do almocreve Belchior, pardo forro, e de Antónia Barbosa, também parda forra ${ }^{1}$.

Segundo testemunhas que a denunciaram, Maria Barbosa saiu de Évora degredada para Angola pelo crime de feitiçaria. Em Angola açoitaram-na publicamente por ser feiticeira e alcoviteira e novamente a degredaram, dessa vez, para Pernambuco, onde de acordo com os denunciantes também "levava mal caminho", passando depois a viver em Salvador, terra onde foi presa em 1612 por ordem do Bispo do Brasil D. Constantino Barradas que a considerava mulher "notoriamente a mais prejudicial e escandalosa que ha nestas partes", e posteriormente enviada pelo Prelado para o Tribunal do Santo Ofício em Lisboa, onde foi julgada por proposições heréticas - embora seu processo esteja repleto de acusações de alcovitice, adultério, práticas associadas a feitiçaria e agressão contra seu marido -.

Ferramenta da centralização do poder monárquico e suporte da reação católica na Contra Reforma, a Inquisição ou Tribunal Santo Ofício, era uma instituição jurídica ligada diretamente tanto ao Rei quanto ao Papa, e foi estabelecida em Portugal em 1536 pela bula Cum ad nihil magis de Paulo III, num momento marcado pelo avanço da colonização portuguesa em vários territórios ultramarinos, bem como pela contestação do protestantismo aos dogmas da Igreja- que nessa altura já se fazia sentir por toda Europa -, e pela ameaça que passou a representar o judaísmo e o islamismo após o monarca D. Manuel, até então rei de Portugal, ter decretado a expulsão de judeus e mouros da terra lusitana (1496) no intuito de consolidar a unificação religiosa sob a égide da Igreja Católica no reino e a obrigatoriedade da fidelidade de toda população sob seu domínio ao Cristianismo apostólico romano.

Nesse cenário de eliminação da heterogeneidade religiosa, Igreja, Coroa e Inquisição atuaram no intuito de garantir a manutenção da ortodoxia entre homens e mulheres desde a vida pública até seus pensamentos mais íntimos, disciplinarizando seus comportamentos e visões de mundo, tanto em Portugal quanto nos seus domínios ultramarinos, como o Brasil, através de um conjunto de normas.

A trajetória de Maria Barbosa dá indícios de uma série de transgressões a essas normas, para compreende-la o trabalho em questão busca investigar os impacto dos discursos da doutrina, da moral católica e das legislações na vida conjugal e sexual das mulheres e homens da colônia, bem como os aparelhos de coerção de práticas desviantes que lhes deram vigência no decurso do século XVII.

\section{MATERIAL E MÉTODOS}

Privilegiando a redução de escala, que principalmente após a gênese dos estudos da micro-história italiana (1960), possibilitaram uma diversificação nos níveis de escala de

\footnotetext{
${ }^{1}$ ANTT, Inquisição de Lisboa, processo 3382.
} 
análises históricas, gerando novas perspectivas de observação como as trajetórias, as biografias e os estudos de caso, utilizei como principal fonte para a pesquisa o processo inquisitorial movido contra Maria Barbosa disponível digitalmente ao público no site do Arquivo Nacional da Torre do Tombo (ANTT): <http://digitarq.arquivos.pt/details?id= $\underline{230303336>}$, cuja leitura e transcrição exigiram um trabalho de tipo paleográfico específico de domínio de palavras e abreviaturas do vocabulário português do século XVII.

Como metodologia básica para o desenvolvimento da pesquisa foi utilizada a análise qualitativa, baseada na leitura de gênero de autoras/res como Joan Scott ${ }^{2}$, Pierre Bourdieu ${ }^{3}$, Carolina Coelho ${ }^{4}$, Susan Moller Okin ${ }^{5}$, Guacira Lopes Louro ${ }^{6}$ e Natalie Davis ${ }^{7}$, que auxiliaram na formulação de questões e problemas relativos ao objeto de estudo.

Foi utilizada também como fonte as Ordenações Filipinas - código legal português promulgado em 1603 pelo rei Filipe I e com vigência até o ano de 1830 -disponíveis de forma já transcritas nos seguintes endereços eletrônicos: <http://www1.ci.uc.pt/ihti/proj/filipinas/or denacores.htm>, bem como a literatura produzida por religiosos e moralistas do período Moderno sobre casamento e vida sexual como a Carta de guia de casados de D. Francisco Manuel de Melo, a obra Espelhos de casados de João de Barros, entre outras através de um corpo bibliografia voltado para esta temática, tais como: ALMEIDA, A. M.. O gosto do pecado - Casamento e sexualidade nos manuais de confessores dos séclos XVI e XVII. $3^{\mathrm{a}}$. ed. LISBOA, PORTUGAL: ROCCO PORTUGAL, 1994.; ULHÔA PIMENTEL, H.. Casamento e sexualidade. A construção das diferenças. 1. ed. Florianópolis: Mulheres, 2012.; SILVA, Maria Beatriz Nizza da. Sistema de casamento no Brasil colonial. São Paulo : Queiroz, 1984.

A leitura da documentação elencada foi orientada ainda pela teoria da Análise do Discurso, de modo que foi procurado ver o texto não enquanto dado, mas em seu funcionamento como produtor de sentido em determinado local e em determinado momento, conforme assinala Orlandi "entender isso é compreender como o texto se constitui em discurso e como este pode ser compreendido em função das formações discursivas que se constituem em função da formação ideológica que as determina"8.

\section{RESULTADOS E/OU DISCUSÃO}

A transferência do matrimônio para a chancela da Igreja representou de acordo com Vainfas uma fórmula encontrada pela Igreja de valorizar a castidade e controlar a sexualidade dos fiéis - questões que provocaram várias discussões entre os teólogos desde o cristianismo primitivo -, garantindo assim sua superioridade e autoridade da matéria espiritual sobre a temporal, visto que, "ao clero, homens do mundo espiritual, deveria caber a castidade e o poder" e "aos leigos, homens do mundo profano, caberia o matrimônio e a obediência"".

\footnotetext{
${ }^{2}$ SCOTT, J.W. . Gênero: uma categoria útil para a análise histórica. Traduzido pela SOS: Corpo e Cidadania. Recife, 1993. Ibidem. Prefácio a Gender and Politics of History. Cadernos Pagu, (3), São Paulo, 1994, p. 11-27. Disponível em: <http://www.pagu.unicamp.br/node/42>. Acesso em: 16 de abril de 2015.

${ }^{3}$ BOURDIEU, Pierre. A dominação masculina. Rio de Janeiro: Bertrand Brasil, 2012.

${ }^{4}$ COELHO, Carolina M. S. . Gênero: teoria e política. Revista de História (UFES), v. 1, p. 13-27, 2009.

${ }^{5}$ OKIN, Susan Moller. Gênero, o público e o privado. In: Revista Estudos Feministas, Florianópolis, vol. 16, ${ }^{\circ}$ 2, maio/agosto 2008.

${ }^{6}$ LOURO, Guacira Lopes. Nas redes do conceito de gênero. In: LOPES, M. J., MEYER, D. E. e WALDOW, V. R. Gênero e Saúde. Porto Alegre, Artes Médicas, 1996.

${ }^{7}$ DAVIS, Natalie Zemon. Culturas do povo: sociedade e cultura no início da França Moderna. 2. ed. São Paulo: Paz e Terra, 2001.

${ }^{8}$ ORLANDI, E.; LAGAZZI-RODRIGUES, S. (orgs). Análise de discurso. In: Introdução às Ciências da Linguagem: Discurso e Textualidade . Campinas: Pontes, 2006, p. 16.

${ }^{9}$ VAINFAS, Ronaldo. Casamento, amor e desejo no ocidente cristão. São Paulo: Ática, 1992, p. 35.
} 
Nessa conjuntura, entrou em prática uma série de regras, sujeitas a punições caso não fossem cumpridas, embasadas ainda pela legislação dos monarcas absolutistas, que orientavam sua realização, seu rompimento, bem como a vida do casal. Através delas é possível perceber como foram produzidas diferenciações entre homens e mulheres, e hierarquias sociais que naturalizavam espaços e modos de ser reproduzidos pela população a partir de concepções que significavam mulheres como lascivas, tentadoras, débeis, fracas, inferiores, subordináveis e, que às colocavam na posição/espaço de serem governadas pelos homens, considerados racionais, fortes e ativos.

Destarte, para que as mulheres não se sustentassem em seus desmanchos e ocupassem devidamente o "papel" de subordinação que lhes foi atribuído por natureza, era considerado direito e dever que seus "responsáveis" lhes aplicassem os seguintes remédios: "treinamento religioso para emparelhar as rédeas da modéstia e da humildade; educação seletiva para mostrar [...] sua moral sem inflamar sua imaginação indisciplinada ou soltar sua língua em público; trabalho honesto para ocupar suas mãos; leis e normas que a sujeitassem a seu marido" ${ }^{10}$, bem como agressões físicas - dentro de determinado limite - para impedir algum mau comportamento ou simplesmente para lembra-las sua preeminência. Elas por seu turno, deveriam teme-los, obedecer em tudo que lhes fosse ordenado honestamente e suportar suas repressões sem replicar.

Esses "remédios" para o desregramento feminino, entretanto, nem sempre serviam para manter as mulheres em "seu lugar", e assim como Natalie Davies que no seu ensaio publicado em 1990 na obra Culturas do povo analisa as inversões sexuais na Europa entre os séculos XIV e XVIII através da vida festiva e da literatura popular, acreditamos que nas circunstancias da vida cotidiana essa imagem da mulher desregrada poderia operar uma ampliação das opções de comportamento e até mesmo sancionar a desordem social ${ }^{11}$. A trajetória de Maria Barbosa nos possibilita pensar essas duas concepções, visto que numa cultura em que a ordem social é dominada pelo princípio masculino, tanto em sua esfera pública - Igreja, Estado, economia, legislação - quanto privada - família e vida íntima -, a forma como ela conduzia sua vida, revela uma "inversão dos referenciais das políticas de gênero do período colonial, que relacionavam o binômio superior/poder dos homens ao inferior/dominado das mulheres" $"$.

\section{CONSIDERAÇÕES FINAIS}

Numa sociedade de grande vigilância e pouca ou nenhuma margem para contestações formais, Maria Barbosa não só criou estratégias para resistir ao casamento indissolúvel/monogâmico e a sexualidade que a Igreja e o Estado impunham enquanto naturais, como afrontou diretamente a instituição eclesiástica com o auxílio dos próprios encarregados de implantar as normas no espaço colonial. Seu cotidiano revela um universo possível, e por vezes contraditório das normas vigentes, dando indícios de que ainda que as punições da Igreja e da Inquisição tenham tentado enquadra-la numa forma de ser mulher fixa, sua vivência demonstra ter sido muito mais dinâmica e plural.

\section{REFERÊNCIAS FONTES MANUSCRITAS:}

\footnotetext{
${ }^{10}$ DAVIS, Natalie Zemon. Culturas do povo: sociedade e cultura no início da França Moderna. 2. ed. São Paulo: Paz e Terra, 2001, p. 108.

${ }^{11}$ Ibidem, p. 112.

${ }^{12}$ REIS, Adriana Dantas. As mulheres negras por cima. O caso de Luzia jeje. Escravidão, família e mobilidade social, Bahia, c. 1780- c.1830. Tese de doutorado. Niterói, Universidade Federal Fluminense, 2010, pp. 2.
} 


\section{- Instituto do Arquivo Nacional da Torre do Tombo (ANTT)}

Processo de Maria Barbosa. Processo número 3382. [1612-1614]. Disponível em: <http://digitarq.dgarq.gov.pt/viewer?id=2303336>. [Último acesso: 31/01/2017].

\section{FONTES IMPRESAS:}

BARROS, João de. Espelho de casados. (1 ${ }^{\mathrm{a}}$ edição 1540) Porto: Imprensa Portuguesa, 1847, pp. XXVI, XXVII e XLVII.

MELLO, Francisco Manuel de. Cartas de Guia de Casados. Londres: Officina de T.C Hansard, Peterboro - Court, Fleet-Street, 1820.

Ordenações Filipinas. Disponível em: <http://www1.ci.uc.pt/ihti/proj/filipinas/or denacores .htm>. Acesso em: 30/06/2017.

\section{BIBLIOGRAFIA:}

ALMEIDA, A. M.. O gosto do pecado - Casamento e sexualidade nos manuais de confessores dos séculos XVI e XVII. $3^{\text {a }}$. ed. Lisboa: Rocco Portugal, 1994.

BOURDIEU, Pierre. A dominação masculina. Rio de Janeiro: Bertrand Brasil, 2012.

BELLINI, Ligia. A coisa obscura: mulher, sodomia e inquisição no Brasil Colonial. São Paulo: Basiliense, 1989.

COELHO, Carolina M. S. . Gênero: teoria e política. Revista de História (UFES), v. 1, p. 13 27, 2009.

LOURO, Guacira Lopes. Nas redes do conceito de gênero. In: LOPES, M. J., MEYER, D. E. e WALDOW, V. R. Gênero e Saúde. Porto Alegre, Artes Médicas, 1996.

MOTT, Luiz. Rosa Egipcíaca: uma santa africana no Brasil. Rio de Janeiro: Bertrand Brasil, 1993.

NOVINSKY, Anita. Inquisição: prisioneiros do Brasil - séculos XVI/XIX. Rio de Janeiro: Expressão e Cultura, 2002.

OKIN, Susan Moller. Gênero, o público e o privado. In: Revista Estudos Feministas, Florianópolis, vol. 16, $\mathrm{n}^{\circ} 2$, maio/agosto 2008.

ORLANDI, E.; LAGAZZI-RODRIGUES, S. (orgs). Análise de discurso. In: Introdução às Ciências da Linguagem: Discurso e Textualidade . Campinas: Pontes, 2006.

PEREIRA, A. M. S. ; REIS, A. D. . A Inquisição no feminino. Mulheres, religião e poder na América colonial. In: Livro de resumos do Simpósio Internacional de Estudos Inquisitoriais/Organização Marco Antônio Nunes da Silva et ali - Feira de Santana: Editora da Universidade Estadual de Feira de Santana, 2013.

PEREIRA, A. M. S. . Inquisição e escravidão. Reflexões em torno do Brasil colonial: Rio de Janeiro, sécs. XVII-XVIII. Plurais: Revista Multidisciplinar da UNEB, 2013.

. A Inquisição no Brasil. Aspectos da sua actuação nas Capitanias do Sul (de meados do séc. XVI ao início do séc. XVIII). 1. ed. Coimbra: Faculdade de Letras da Universidade de Coimbra, 2006.

REIS, Adriana Dantas. As mulheres negras por cima. O caso de Luzia jeje. Escravidão, família e mobilidade social, Bahia, c. 1780- c.1830. Tese de doutorado. Niterói, Universidade Federal Fluminense, 2010.

SOUZA, Laura de Mello e. O diabo e terra de Santa Cruz: feitiçaria e religiosidade popular no Brasil colonial. São Paulo: Companhia da Letras, 1986.

SCOTT, J.W. . Gênero: uma categoria útil para a análise histórica. Traduzido pela SOS: Corpo e Cidadania. Recife, 1993.

VAINFAS, Ronaldo. Casamento, amor e desejo no ocidente cristão. São Paulo: Ática, 1992.

ULHÔA PIMENTEL, H.. Casamento e sexualidade. A construção das diferenças. 1. ed. Florianópolis: Mulheres, 2012.; SILVA, Maria Beatriz Nizza da. Sistema de casamento no Brasil colonial. São Paulo : Queiroz, 1984. 